\title{
ASSISTIR PARA TRANSFORMAR (-SE): A POTÊNCIADA ESCOLA NA LUTA PELO RECONHECIMENTO SOCIAL DAS JUVENTUDES EM SITUAÇÃO DE RUA
}

\author{
Josiane Machado Godinho
}

Resumo: O presente artigo tem por objetivo apresentar as transformações que surgiram como uma grande potência para a permanência de jovens em situação de rua, na escola. A partir das análises da pesquisa com jovens estudantes que se encontram em situação de rua, professores/as, e equipe pedagógica e diretiva da Escola Municipal Porto Alegre, da Rede Municipal de Porto Alegre/RS, na qual são atendidos, além desses jovens, moradores/as de abrigos e de comunidades distantes da região central, por meio da contribuição para a emancipação através da educação, auxilio na construção da autoestima dos/as estudantes, viabilização do acesso aos seus direitos enquanto jovens cidadãos/ãs e possibilidade de novas maneiras de relacionarem-se consigo e com o mundo. Tendo em vista 0 público que recebe, a Escola Porto Alegre, pouco a pouco, foi se modificando para atendê-lo e, nessa mesma medida, diferenciando-se das outras escolas da Rede Municipal. A busca pela escolarização e pelo espaço institucional é, antes de lutar por um direito que Ihes fora negado, buscar o reconhecimento recíproco participando ativamente da vida social. O espaço em questão, com seu caráter genuinamente escolar, consegue operar na luta pelo reconhecimento social dos/as estudantes, com ideais fora dos padrões da rede a qual atende, contrapondo o lado mais pesado da balança.

Palavras-chave: Juventudes em situação de rua. Escolarização. Reconhecimento Social.

\section{ATTEND TO TRANSFORM: THE SCHOOL POTENTIAL ON THE FIGHT FOR THE SOCIAL ACKNOWLEDGMENT OF THE YOUTH IN STREET SITUATION}

\begin{abstract}
The present article aims to introduce the transformations that emerged as a high potentiality for the permanence at the school of the young on the street. Through the analysis of the research made with the young students in situation ons the streets, teachers, pedagogical and directive team of the Porto Alegre's Municipal School, from the Porto Alegre's Municipal Network, which they are attended, beyond these young, residents of the shelters and comunnities that are far away from the central area. By the contribution for the emancipation through the education, support on construction of the students self-steem, viabilization for them to access their rights as young citizens and the possibility of new ways to
\end{abstract}

\footnotetext{
${ }^{1}$ Doutoranda/bolsista CAPES no Programa de Pós-Graduação em Educação da Pontifícia Universidade Católica do Rio Grande do Sul.
} 
relate with themselves and to the world. To the point of view from the public received, Porto Alegre's school, step by step, was going to modificate itself to attend them and, for consequence, differing from the other schools from the Municipal Network. The search for the schooling and institutional space is, before fight for their rights that has being denied, to search the reciprocal acknowledgment participating actively on the social life. The space in question, with its genuinely school character, can operate on the fight for the social acknowledgment of the students, with ideals outside the standards of the network which it attend, opposing the heavier side of the balance.

Keywords: Young in homeless situation . Schooling. Social Recognition.

\section{INTRODUÇÃO}

Tendo em vista o público que recebe, a Escola Porto Alegre, pouco a pouco, foi se transformando para atendê-lo e, nessa mesma medida, diferenciando-se das outras escolas da Rede Municipal de Porto Alegre. Para expressão dessas mudanças, trago, juntamente com as respostas de grupo focal e de entrevistas, momentos e conversas que digam das relações humanas e institucionais que os/as jovens experimentam na escola. Conforme conta a Gestora Sílvia: Eles vinham sujos, vinham com dor, vinham extremamente drogados, usavam dentro da sala de aula, e eu chegava perto, tinha aquele paninho molhado de loló. Ele não tinham ninguém que acolhesse... Com o tempo as necessidades foram surgindo.

Como sugere a professora, acolher pessoas em situação de rua exigia algumas especificidades que gradualmente complementavam o tempo e os espaços pedagógicos e administrativos da escola, e isso parece ter dado certo. Digo isso quando comparo a saga de outras escolas por onde passei: fazer o/a estudante chegar no horário, não pular o muro para ir embora, permanecer sentado durante quase quatro horas ouvindo, ou implorando para que interaja quando não imploram, dão pontos por participação. Na EPA, nem sempre o dia ocorre conforme se deseja, porém, percebo que os percalços diários são vistos com outras lentes, não por todos/as que constituem a escola, mas como se respira acolhimento na instituição, esses/as acabam perdendo as forças.

Ainda lembro que uma estudante abriu a bolsa e me disse: Sabia que eu 
tenho sabonete próprio? Dizendo isso, foi para o banho e retornou para a sala minutos depois com roupas limpas e os cabelos molhados - ela parecia mais bonita e descansada. E banhou-se com seu próprio sabonete que carregava na bolsa, não com o que todos os outros colegas usavam. Depois desse dia passei a observar o quanto essas atenções eram necessárias para os/as estudantes e importantes para toda a escola. Notei que quando não havia tempo para o banho, para o caso de quem chegasse atrasado, muitos/as reclamavam, iam para o pátio e se dispersavam - o que afetava diretamente o desenvolvimento em sala de aula:

\begin{abstract}
Chegar na escola, poder tomar um banho, tomar um café, saciar as necessidades básicas e ir para uma aula te sentindo bem, é outra coisa. Quem não se sente melhor assim? Se tu $f$ icar chateado, ter um espaço de escuta. A gente foi vendo enquanto grupo de profes que isso era necessário. Tudo bem, tu precisa construir neles a autonomia para que eles procurem o que lhes é de direito na rede, mas a autonomia a gente tb constrói dentro da escola e pra isso o estudante precisa tá inteiro. (G. Paula)
\end{abstract}

Entretanto, nas minhas andanças pela EPA, ouvia muito sobre como a escola era assistencialista com os/as estudantes, no sentido de que essa assistência tivesse mais importância que a educação, na escola. Sobre isso a gestora Paula também explica: Tem que se tirar esses dogmas que porque tu ta garantindo um banho, eu estou perdendo o valor de educação, não. Eu estou agregando valor da educação. Um banho tem muito mais sentido pra uma aula de ciências que ficar estudando as células. E continua:

Há uma prática assistencialista por um lado, mas ela não é assistencialista de deixar o sujeito no mesmo lugar, é de reconhecer onde ele ta e de estar lá, politicamente, garantindo direitos. Assistencialismo, se a minha única ideia é dar conforto e acabou. Um conforto temporário. Não assistencialista, mas sim, para além da educação formal quando eu quero botar ele, enquanto cidadão de direitos e, enquanto escola, poder apoiar para que ele garanta a execução do seu direito. (G. Paula)

Sobre essa rotina, o Projeto Político Pedagógico da EPA prevê, além do banho, outrasações de acolhimento:

Conversa e escuta; Café diferenciado; Encaminhamento e atendimento de saúde; Após uma avaliação da equipe do SAIA ${ }^{3}$, o estudante será inserido nas atividades (seja nas totalidades, nas aulas especializadas ou nas atividades coletivas); Contatos com os serviços para obter informações e/ou propor novos encaminhamentos. (PPP. p.36) 
E essas ações, durante o grupo focal realizado com os/as estudantes, fizeram parte dos registros que surgiram como um grande potencial para a permanência deles/as na escola. Como na seguinte fala: Eu me adaptei aqui na EPA e não quero sair mais... O cara chega e toma banho, depois almoça, vai pra informática, faz pouca coisa na sala. Eu comecei a curtir! (E. Camilo)

Potência reconhecida pelos/as trabalhadores/as da escola, como na fala da Gestora Sílvia, que reconhece a importância das ações de acolhimento e corrobora com a fala do estudante, já citado em um dos capítulos anteriores, ao afirmar que contavam apenas com Ó Centro como forma de acolhimento:

\begin{abstract}
O nosso estudante eu enxergo como um todo, inteiro. Aí eu fico pensando, ele vem da rua, qual a condição que esse cidadão vai ter, entrando aqui se sentindo mal, com mau cheiro, com fome, com dor. Se eu não tiver esse sujeito inteiro eu não vou conseguir dar aula. Quando eu cheguei nessa escola eles vinham direto debaixo da ponte, chegavam aqui e nós não tínhamos isso de banho a gente só tinha o Ó Centro que era lá na Julio de Castilhos. (G. Sílvia)
\end{abstract}

Ao questionar os/as estudantes sobre as diferenças entre a EPA e outras escolas por onde tenhampassado, surgiram novamente as ações de acolhimento da escola como um grande diferencial: É que uma coisa que os guris não disseram é que se tu parar pensar: não tem um colégio que te dá banho quente, comida na hora de chegar, que tu faz o que tu quiser dentro do colégio. (E. Taís).

Após a fala da estudante Taís, indaguei sobre o que eles/as fazem na EPA que não podem fazer em outras escolas, referindo-me ao: "tu faz o que tu quiser dentro do colégio". E, a partir disso, surgiram outras ações na falas: Em outro colégio não deixam a pessoa fumar dentro do intervalo. E, também: dão cafezinho preto antes de tu ir pra sala de aula! (E. Taís) Referindo-se assim a política de redução de danos adotada pela escola, conforme consta no PPP:

O cardápio proposto para as refeições da EPA também tem seu diferencial. As refeições que são pensadas pela Equipe de Nutrição considerando, em muitos casos, as condições precárias

de alimentação nos espaços alheios à escola. $O$ oferecimento de café aos estudantes compõe também outro diferencial da escola, já que os seus efeitos ajudam a minimizar o sono, a abstinência de substâncias 


\begin{abstract}
psicoativas e a auxiliar na concentração durante as atividades escolares. Esta e outras ações em conformidade com a filosofia da Redução de Danos, ajudam a minimizar os efeitos da falta das drogas, contribuindo para a manutenção dos estudantes por um período mais prolongado na escola, garantindo o acesso e a permanência à mesma. (PPP. P.6)
\end{abstract}

Pode parecer curioso para quem chega e observa as práticas adotadas pela escola para promover a permanência dos/as estudantes. Fumar cigarro na escola e tomar café antes de entrar para aula dói aos olhos de quem vê pela primeira vez. E, até compreendermos que essas práticas, além de legais, são pensadas para o bem estar dos/as estudantes, demora um pouco. Porém, depois de já conhecidas e interiorizadas, passamos a estranhar as regras, algumas vezes tão duras, de outras escolas

- exponho isso porque esses/as jovens os/as quais entrevistei já passaram por outras instituições nas comunidades de origem.

Percebo, a partir desses relatos, que o tempo com pessoas em situação de rua, experienciadas pela EPA, é que a tornou diferente de outras escolas para os/as estudantes. Como se o discurso, pedagogicamente correto, de que a escola deve se adaptar as necessidades dos/as estudantes tivesse dado certo. Essa organização diferenciada adotada pela escola é citada no Projeto Político Pedagógico:

\footnotetext{
Constitui-se num espaço de acolhimento, organização e socialização dos saberes, que atende para além da escolarização formal, com uma metodologia própria e tendo também como diferenciais o Serviço de Acolhimento, Integração e Acompanhamento/SAIA e o Núcleo de Trabalho Educativo/NTE. (PPP. p.4)
}

Conforme já me referi, fazem parte das ações de acolhimento, também, encaminhamento e atendimento à saúde. Isso vi na prática. Durante uma atividade no pátio, umas das estudantes machucou o braço e no outro dia, por ainda queixar-se de dor, foram chamados os profissionais da saúde para ajudála. Observei que eles chegaram rapidamente na escola, e eram três pessoas. Três pessoas somente para ela, fora todo o grupo da escola que, ora acariciavam seus cabelos, ora Ihe diziam palavras de conforto. Tempo depois a equipe de 
atendimento foi embora e eu perguntei para outro estudante - como se já não soubesse a resposta - por que eles/as não vão até o posto de saúde ao invés de equipe vir até a escola, já que a jovem tinha passado a noite com dor. E ele me disse o já esperado: sozinhos/as não seriam atendidos. O que veio a confirmarse na entrevista com a Gestora Paula: Como eles dizem: se não for com as costas quentes eu não sou atendido, e nós somos as costas quentes.

Percebo que a escola em questão usa de todos os meios para não acontecer novamente com o/a estudante, o que já havia acontecido em suas outras passagens pela escola: o abandono. Daí, toda a preparação e esforço para que o/a estudante se sinta bem e permaneça na escola. Porém, em meio a todos esses esforços, há o/a professor/a que está lá para ensinar e que representa, historicamente, detentor/a do poder e sabedoria, e que espera por estudantes sedentos de vontade de aprender:

Tem momentos em que eu me pergunto, que esgota tanto o limite institucional e o limite das pessoas, com aquele cara, por exemplo, que vem constantemente tomar seu banho. E que o vínculo parece que é só aquele. E que a gente se questiona, que é professor e que teve sua formação: cadê aquilo que eu vim fazer aqui? (G.Paula)

O paradoxo entre a assistência que viabiliza a permanência do/a estudante e educação que é a razão de ser da escola parece ser uma preocupação somente da equipe pedagogia e do/as professores/as: Eu quero terminar meus estudos, o mais rápido possível. A escola oferece a você sair fora da rua do jeito que você ta, sem forçar nada, é automático assim... você vai se desenvolvendo... É um incentivo ao aprendizado para as pessoas que tão mais necessitada. (E. Lucas). Os/as estudantes, durante todo o grupo focal apontaram muitas vezes o desejo de estudar para poder trabalhar, para entender a história do lugar onde vivem e, também, utilizar, na rua, a matemática que aprendem na escola. $E$, mais do que isso, se reconheciam como pessoas que precisavam daquele espaço e do acolhimento diferenciado proporcionado pela EPA para se autorreciclar.

Para os/as estudantes, a Escola Ihes confere a chance de se autorreciclar. Assim, estar na escola pressupõe uma mudança de estado, como se lá tivessem a oportunidade de potencializar o que já sabem e tornarem-se melhores. 
Conforme a seguinte fala: $A$ escola oferece pra você sair fora da rua do jeito que você tá mesmo. Você acaba se desenvolvendo. (E.Camilo). Proporcionando, até mesmo,

oportunidades para que deixem de ter a rua como local de moradia, como na fala da gestora: A gente não tira eles da rua, nós criamos possibilidades. E se ele assim o puder, quem sabe ele consiga. Não somos onipotentes, mas temos potência para isso. (G. Paula)

Durante a entrevista com a Paula, a rua, em nenhum momento foi citada como algo ruim, triste. Mas sim, como algo a ser superado pelo/a estudante, e a escola como um primeiro passo para sair dela. Reconheci esse posicionamento, também, na fala de outros/as entrevistados/as: Quando a gente conhece as histórias tu percebe que a rua foi a salvação. Não é o olhar romântico, eu posso ter jeitos de ficar na rua. (G. Sílvia)

Torna-se mais fácil compreender a opinião da Gestora Paula depois que, cotidianamente, vamos conhecendo a história de cada um dos/as jovens. Como o Daniel, que desde muito pequeno frequenta a EPA, com o qual conversei durante a cerimônia de formatura dos/as estudantes em dezembro de 2013. Naquele dia ele contou-me que passaria o final de semana na casa da mãe. Ingenuamente pensei que essa poderia ser uma oportunidade para ele sair da rua, um recomeço - Coisa boa, Dani! Então tu vais ficar lá com ela? A resposta foi negativa. Disse que já estava desde os nove anos de idade na rua e que não voltaria mais para a casa da mãe. Antes que eu o convencesse de que a casa da mãe certamente é muito melhor que a rua, ele apontou para as marcas no seu corpo e me disse: $T a$ vendo isso aqui ó? Foi tudo ela que fez! Desisti naquele momento, não tínhamos a mesma mãe e, se tivéssemos, eu também não voltaria.

O exemplo acima mostra que pode ser menos dolorido estar na rua, do que com a família: Quem disse que a rua só é lugar de sofrimento? A rua também é lugar de solidariedade. (G. Paula) Entretanto, a mesma gestora pondera: Para uma criança ou adolescente a rua não é um espaço cuidador, é um espaço de violação. Esse contra-senso apresentado pela diretora revela o quanto a 
instituição é conhecedora das histórias desses jovens, pois elas, muitas vezes, se repetem. E sabem que estar em casa pode ser tão violento que a rua - também considerada local de violação- torna-se solidária para quem precisa dela.

Dessa forma, a EPA dá a sua contribuição ao oferecer o espaço institucional e humano no qual esses/as jovens têm a oportunidade de se constituir como sujeitos de direitos, sem a condição de abandonar o que foi construído solidariamente com a rua e tudo que faz parte dela, como expõe a gestora: $A$ EPA pode dar para esse sujeito um sentido de estar na rua, e não deixar ele perder a identidade de cidadão. (G. Paula)

Assim, autorreciclar-se é poder construir-se a partir do desejo de fazê-lo e não da necessidade, que outrora o/a levou à rua. E o mais importante, ter a oportunidade de reconstruir-se: O EPA é o único colégio que aceita moradores de rua, porque os outros já fecharam. (E. Camilo) O que atribui a EPA um lugar como a casa da mãe, um lugarde afeto.

Em entrevista com a gestora Sílvia, logo nos primeiros minutos ela me questionou: Sabe quando tu ta na casa da mãe? A fim de exemplificar como é a relação entre a EPA e os/as estudantes. Já na conversa com os/as jovens, essa relação foi representada como um elo com o passado, assim como no caso desta jovem: Eu morei no abrigo e vários estudaram aqui, a minha irmã também estudou aqui. (E. Taís) Ou do jovem que conta a sua história junto com a história da escola: o Juarez me conhece desde pequenininho!

E a escola reconhece esse papel de protetora junto aos/às estudantes: Quando mais frágeis os sujeitos, mais vínculos eles têm com a EPA. É tu não ser um mero serviço. É o acolhimento, tu não é uma estatística de atendimento. E também durante sua fala demonstrou que a EPA age de maneira a reconstruir as relações que eles/as têm com outras instituições: Toda a escola hoje é um espaço de proteção à criança. A EPA é um espaço maior porque lá quando a escola deveria ter sido para esses sujeitos, ela não foi (G. Paula). O que possibilita que os/as estudantes possam, novamente, criar vínculos institucionais com a família, abrigos e a própria escola. 
E essa tarefa não parece excluir o caráter de escolarização que a EPA tem para os/as estudantes, pois promove a conclusão dos estudos para a superação das dificuldades que encontram na rua. $E$ uma dessas dificuldades creio que seja a falta de oportunidades de trabalho juntamente com a necessidade dele, visto que precisam garantir seu sustento. Pois, ao questioná - los/las sobre o motivo pelo qual estão estudando, eles/as responderam:

- Pra mim é, por que eu to pensando em trabalhar e eles pedem todo o fundamental. (E. Gabriel) (E. Camilo)

Pra ti arrumar dinheiro só traf icando ou roubando ou matando. .

Pra mim é pra largar o crime de mão, pra poder pegar um serviço, pra ser cobrador ou jardineiro. . (E. Fábio)

Pra arrumar um serviço pra sair da rua. (E. Vicente)

Terminar mais rápido possível. (E. Lucas)

Curiosamente, foram pouco frequentes esses anseios pela conclusão dos estudos quando em conversas mais próximas. Nessas, contavam do desespero por perder o vínculo com a instituição, como se isso significasse perder, também, a condição de cidadãos/ãs dada pela escola. Como o estudante João que, ao me encontrar na rua, fez questão de relatar sua indignação por estar entre os formandos de 2014: Eles querem me formar agora, mas eu já disse que não quero! Diante da reclamação, resgatei a formatura como a conclusão de uma etapa de estudo e dedicação que ele teve na escola. Em vão, João estava inconsolável. Tempo depois, ao encontrá-lo novamente na rua, tamanha foi a minha tristeza ao vê-lo: estava mais magro, cabelos grandes e despenteados e roupas sujas. Como havia anunciado, a formatura não lhe fez bem.

Essa pequena ilustração vem ao encontro da fala da gestora Sílvia que assegura: o objetivo nunca é o estudo, raramente. Tem aquele que vem para um espaço protegido, se sentem respeitados, ouvidos. Essa proteção, nesse caso, é visualmente perceptível.

Entretanto, mesmo que a Instituição não seja para os/as estudantes o lugar onde especialmente se aprende conteúdos escolares, a forma como são 
conduzidas as práticas possibilitam a permanência dos/as estudantes, para que assim possa acontecer a aprendizagem. Portanto, sentir-se respeitado e ouvido, pode ser a primeiro passo para reatar o vínculo com a escola.

Essa possibilidade exige outras maneiras de ensinar: Eu sempre tento trazer para asquestões que eles vivenciam, mas isso eu falo do meu trabalho. Mas é um exercício complicado porque tu tens que estar aberto a isso. (P. Renata) E, quando disponíveis às outras maneiras de ensinar, o planejamento passa a ser constantemente revisitado: Tu até vem com um planejamento, uma ideia.. mas surgem outras questões. E completa: Eu faço o planejamento fechadinho para aquela aula. Não que não tenho uma continuidade, mas tem que ter inicio, meio e fim (P. Renata) Sobre reconhecer os diversos modos que exige o público da escola, a gestora Sílvia afirma: O turno da manhã é mais fácil. Eles conhecem o estudante porque passam a manhã inteira com eles. Mas com os professores de área é muito complicado, pois eles trabalham muito fragmentados, até eles se engajarem num projeto; Nesse relato, se resume a principal dificuldade encontrada pela equipe diretiva com os profissionais que lá atuam: o desconhecimento sobre a escola. Pois muitos deles, por completarem sua carga horária em outras escolas, ficam, em alguns casos, apenas 10 horas semanais na EPA, impossibilitando que possam apropriar-se do espaço e trabalharem em consonância com o projeto pedagógico proposto pela escola. E salienta a gestora: Como seria bom se cada professor de sala de aula conhecesse bem e entendesse lá dentro como a gente entende aqui. (G. Sílvia).

Contudo, na entrevista realizada com dois profissionais, o professor - cuja disciplina pertence às Totalidades Finais - afirmou, ao mencionar suas experiências em outras escolas da rede municipal de ensino e da rede privada, que na EPA a aprendizagem é mais rápida, conforme segue a fala: Eu dei em um mês de aula aqui, o que eu não dei num semestre inteiro numa $C 3$ em outra escola. Aqui é mais rápido e elesaprendem (P. Marcelo).

E, a propósito das diferenças entre os/as estudantes da EPA e os/as estudantes de outras escolas, a professora Renata afirma: Esses alunos daqui, 
mais que outros a rede, percebem coisas que são veladas, que outros alunos não perceberiam. Um olhar de reprovação, uma fala, uma palavra ou qualquer menosprezo tu já não consegue ter a empatia do grupo. O que corroborou com a seguinte afirmação da gestora Paula:

\begin{abstract}
Tem professores que fazem a seleção aqui dentro, or exemplo: esse estudante é muito bem recebido na minha aula. Este não é. Quando a gente olha os bem recebidos são os cheirosinhos, bonitinhos. Os que não são, são os que jogam a rua na tua cara. Esse não entra, não avança.
\end{abstract}

A dura argumentação que citei acima dá indícios que nem sempre todos/as são acolhidos nessa casa. Ou, que nem todos/as são recebidos de forma igualitária. Esses/as, os/as — que jogam a rua na carall, trazem cotidianamente a realidade em que vivem, para dentro da escola. Interessante observar que foi essa mesma realidade que tornou a EPA, a escola que é hoje - realidade que incomodava em outras instituições e que fez dela, um refúgio. Todavia, a reação causada pelos/as que não são cheirosinhos e bonitinhos, também seleciona, de certa forma, os/as professores: A primeira coisa que eles fazem é meter medo. Mas depois eles vão mudando. Mas o professor também tem que mudar. Temos gente que ficaram apenas um ano, tem que ficou 2 ou 3 anos. E tem quem está aqui há muito tempo. (G. Sílvia).

Como educadora que sou, não posso deixar de ponderar a complexa e desafiadora arte de viver essa casa. Pois, juntamente com nosso ofício, estão nossos medos, desejos, expectativas e uma série de outros sentidos e sentimentos que não acompanham o botão de desligar. Há ali, se nos dispusermos a isso, um longo caminho de aprendizagens e de constantes visitas aos nossos conceitos. Observei, durante o tempo que permaneci na escola, que havia um grande respeito com os/as educadores/as e um entendimento que nem todos/as estavam preparados, desde o início, para a proposta da escola: Esse é o problema da EPA, a gente tem projeto, mas somos uma ilha no país. O que fazer com esse professor que vem de um oceano enorme e coloca ele numa ilha. (G. Paula). A respeito disso, a gestora Sílvia alerta de que é uma escolha fazer parte da escola: Existe o cuidado com o cuidador. Como é que tu também não vai ouvir quem ta 
ali pedindo socorro. Mas esse é o perfil do nosso estudante e o professor pode escolher.

Há, porém, jovens que não são o perfil da Instituição - aqueles/as que, excluídos/as da escola, são novamente excluídos/as na EPA. Percebi que esses/as, são os/as que, verdadeiramente, causam medo nos/as 76 trabalhadores/as: Eu não to aqui pra apanhar de aluno (P.Marcelo). Esse relato, profundamente desesperançoso, foi provocado pelo questionamento que fiz a respeito dos/as estudantes que eram proibidos de entrar na escola - na ocasião, dei o exemplo de um estudante que não poderia mais entrar e de outro estudante que havia sido suspenso poralguns dias. $E$ ao questionar quais os critérios usados para decidir quem não pode entrar, a gestora Paula afirma: É quando esse sujeito impossibilita outros de estarem aqui dentro, porque vende, trafica, é agressivo tanto com os professores, quanto para os colegas. É quando chega ao limite de não respeitar aqueles que estão ali. Não é o limite dele, mas o limite da Instituição.

Essas medidas restritivas são adotadas a fim de proteger tanto os/as professores/as, quanto os estudantes - pois, há casos em que um/a estudante impede outros/as de estarem frequentando a escola.

No entanto, mesmo categórica com tal afirmação, transpareceu o desconforto de Paula ao falarsobre esses/as jovens, uma vez que a escola decide pela exclusão, em uma instituição pensada para incluir os já excluídos. É como na casa da mãe. A mãe que cuida, que acolhe, que protege, que ensina e que castiga.

Não houve um só dia em que eu, ao chegar à escola, não avistasse, já de longe, estudantes no portão. E a espera era sempre para entrar: a espera pelo guarda com as chaves do portão; a espera por seu turno de atividade; a espera que alguém os recebesse - às vezes percebia que a rua, de tão grande, tornava esse muro mais confortável, confiável. Era intrigante sentir que um cadeado pudesse ser saudável para uma escola. Porém, imagino que seja a mesma sensação de estar chaveando a porta ao chegar em casa - o mesmo desejo de abrigo saciado de maneiras diferentes. 
E existiam outras coisas - estar na Escola pressupunha mais que somente estudar. Prova disso foi o relato de Daniel na primeira reunião na Câmara de Vereadores, que tratava do possível fechamento da Escola. Disse ele, para mais de duzentas pessoas, que o que mais queria era que a escola se mantivesse aberta para que ele pudesse se formar e retornar para a casa da mãe. Enorme foi o meu espanto, pois, como já narrei anteriormente, Daniel já vive na rua desde os nove anos de idade e pelos maus-tratos que sofreu na infância não desejava reatar o vínculo com a mãe. Após a reunião, por conhecer o seu jeito acanhado, parabenizei-o pela coragem de falar a todas aquelas pessoas e perguntei por que havia dito que voltaria para casa da mãe - se em mais cinco anos que nos conhecemos, tantas foram as vezes que me confessou que não iria se formar para não perder o vínculo com a escola e porque não queria voltar para a família. Ele respondeu: Por que sim né, Josi! Muito pensei sobre esta resposta e foi com um misto de espanto e admiração que percebi que Daniel aprendera as regras do jogo. Compreendeu que, para aquela ocasião, não convenceria os representantes da importância da escola, pela formação e acolhimento diferenciados que a Escola oferta. Mas sim, pela oportunidade de conclusão do Ensino Fundamental, incluindo aí a inserção no mundo do trabalho e retorno para as suas comunidades: Ao dizer o quanto era importante permanecer na escola não somente para estudar e formar-se, optou por sensibilizá-los, agregando ao seu discurso, o retorno à casa da mãe que talvez fosse, exatamente, o que eles queriam escutar.

Essas outras coisas, não ditas e pelo Daniel, mas que foraminúmeras vezes marcadas nas falas e nas ações dos/as estudantes e trabalhadores/as da escola durante a pesquisa, é que tornam a EPA uma escola de outro jeito. Que, pensada para pessoas em extrema vulnerabilidade, proporciona uma outra maneira de relacionar-se com a vida, com seusdireitos, com o outro.

As condições de desigualdade que vivem os/as estudantes em situação de rua, ligadas às experiências de maus-tratos, discriminação e desrespeito, é diretamente relacionada à ausência de reconhecimento social, apontado por Honneth, ou seja, não somente a extrema pobreza é o principal motivo das lutas 
que combatem cotidianamente. Há situações conflitivas enfrentadas por esses/as jovens que geram, frequentemente, experiências de exclusão e menosprezo.

Essa e outras situações de desrespeito enfrentadas pelas juventudes em situação de rua, tratadas por Honneth (2003) como uma forma de não reconhecimento, são os primeiros passos para as resistências sociais. A dimensão que podem tomar, muitas vezes, colabora para importantes avanços na sociedade. E essas lutas por reconhecimento podem, além de contribuir para importantes avanços, colaborar para a construção da autonomia dos sujeitos.

E são nessas situações que a EPA consegue repensar-se e intervir a fim de minimizar as injustiças sociais que vivem esses/as jovens - trazendo para a escola o direito a consultas médicas, o direito de ter documentos, de usar roupas limpas e de ser chamado pelo nome. Oportunizando um espaço de luta por reconhecimento social, que só ocorre porque, muitas vezes, esse reconhecimento não acontece. Assim, a EPA contribui para a emancipação através da educação, auxiliando na construção da autoestima dos/as estudantes, viabilizando o acesso aos seus direitos enquanto jovens cidadãos/ãs e possibilitando novas maneiras de relacionarem-se consigo e com o mundo.

\section{Referências}

HONNETH, Axel. Luta por reconhecimento: a gramática moral dos conflitos sociais. Tradução de Luiz Repa. São Paulo: Ed. 34, 2003. Título original: Kampf um Anerkennunng.

PORTO ALEGRE. Prefeitura Municipal. Secretaria Municipal de Educação: Projeto Político Pedagógico: Escola Municipal Porto Alegre. Porto Alegre, 2013. 